\title{
Dossiê
}

\footnotetext{
Resumo

A presença de fantoches em dispositivos psicoterapêuticos existe há quase um século, e podemos dizer que boje está entre as mediações frequentemente utilizadas no tratamento de crianças, bem como de adultos. Neste artigo, vamos nos concentrar no campo da psicopatologia clinica e no lugar que pode ser atribuido ao fantoche no encontro com as questões que atravessam a prática de um hospital-dia para crianças de um Centro Médico-psicológico (CMP).

Descritores: terapia com fantoches; mediação terapêutica; sofrimento psíquico; psicopatologia clínica.
}

\section{O FANTOCHE COMO MEDIAÇÃO PARA OS SOFRIMENTOS PSÍQUICOS}

\author{
Pascal Le Maléfan \\ Teresa Rebelo

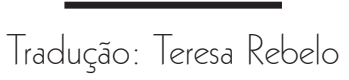

DOl: http://dxdoi.org/10.11606/issn. 1981-1624.v20i2p194-204.

s fantoches existem nos dispositivos terapêuticos há mais de um século, e podemos afirmar que são mediações frequentes no tratamento tanto de crianças quanto de adultos. Tal fato é concomitante à evolução das artes do fantoche, o que dá a esse tipo de mediação uma nova dimensão capaz de questionar os impasses e as perspectivas da modernidade. Os temas do fantoche contemporâneo são a morte, a alienação, o domínio e a dissociação, assim como a ética do outro, a revolta e a subversão do objeto de consumo.

Três possibilidades aparecem: o fantoche como elemento central de um dispositivo, com objetivo criativo ou terapêutico; como um elemento entre diversos outros, integrando um dispositivo da relação terapêutica ou psicoterapêutica; ou ainda, o que é mais raro, como único vetor de uma relação terapêutica ou psicoterapêutica.

- Psicólogo e psicanalista. Professor e pesquisador do Laboratório de Psicologia e Neurociências da Cognição e Afetividade (PSY-NCA) da Universidade de Rouen, Mont-Saint-Aignan, França.

- - Psicóloga. Professora e pesquisadora do Laboratório de Psicologia e Neurociências da Cognição e Afetividade (PSY-NCA) da Universidade de Rouen, Mont-Saint-Aignan, França. 
Essas três possibilidades correspondem: às oficinas terapêuticas e aos grupos terapêuticos com mediação; às psicoterapias lúdicas ou à orientação psicanalítica; e à utilização lúdica (sem fins terapêuticos) ou na informação médica.

Neste artigo, vamos nos concentrar no campo da psicopatologia clínica e no lugar que pode ser atribuído ao fantoche no encontro com as problemáticas que lhe são próprias. Assim, são essas as duas primeiras possibilidades que serão desenvolvidas, a partir de uma prática clínica em hospital-dia para crianças em um Centro Médicopsicológico $(\mathrm{CMP})^{1}$.

\section{Uma prática clínica com fantoches}

Comecemos com a prática clínica comum de um psicólogo clínico psicanalista em CMP. Como sabemos, as razões do encontro com um psicólogo nesse tipo de tratamento são várias e diversas, sendo que, onde trabalhamos, pode acontecer em uma primeira consulta ou após uma consulta médica. Para as famílias, aceitar ou solicitar uma consulta com um psicólogo para uma criança ou adolescente corresponde a consentir em falar sobre o que não vai bem, e, logo, sobre as razões de fundo, que são de vida ou de morte; dos impasses e das possibilidades de ultrapassá-los. Nada que seja banal, pois o sofrimento está sempre presente.

No entanto, alguns sujeitos são reticentes ao se expressar ou, mesmo aceitando o encontro sem recusar o vínculo, têm um uso problemático da linguagem, sendo várias as razões pelas quais a linguagem não lhes é confortável. É nesse momento que o fantoche entra em cena como intermediário, como suporte à fala. Diríamos antes: "pode entrar em cena". A escolha de ter os fantoches entre os objetos/jogos à disposição dos pacientes é uma escolha pessoal. Outros clínicos não o fazem ou fazem outras escolhas que consideram desde uma relação especial a um modo de expressão. É um aspecto importante. Se os fantoches estão presentes no equipamento (objetos/jogos) que propomos, é porque temos uma relação especial com eles, o que faz com que eles, assim como a sua singularidade, nos sejam familiares. Chamamos isso de abertura a um modo de significação, que une o movimento à fala. Trata-se da aposta de que o movimento irá preceder e acompanhar uma fala, pois a cadeia de 
significantes passando pela voz seguirá a cadeia de significantes do movimento. Dar a oportunidade a um sujeito de pegar em um fantoche - neste caso, um fantoche que cobre a mão como uma luva - é apostar que ele se verá e se ouvirá lá onde ele não está, fazendo uma paráfrase de Paul Valéry ${ }^{2}$. Essa experiência de não-eu (Valéry, mais uma vez) está na origem de toda a utilização de fantoches e é a base do seu uso terapêutico, mas também é apostar que o movimento possui significado diferenciado, baseado na gramática que os artistas do Teatro de fantoches criaram.

Expor os fantoches em um dispositivo psicoterapêutico é também propor ao sujeito se virar para um mundo criativo, onde pode se ouvir de um ponto que ele mesmo desconhece e para um tipo discursivo onde a fala não é o único meio de mobilizar os significantes. $\mathrm{Na}$ língua dos fantoches, trata-se de um distanciamento anunciado e da projeção/manipulação. Mas, mesmo se o fantoche pertence ao registro de ícone, o que reforça sua inscrição na sua dimensão imaginária e no movimento, as convenções que o sustentam e o produzem são totalmente estruturadas pelas leis da linguagem e dependem de três registros RSI, resultando que a ação e o que dela decorre constituem um discurso ${ }^{3}$. E essa é sua originalidade nas maneiras de produzir a simbolização e na retomada do processo de subjetivação. Quando as palavras não podem reduzir o inominável, colocá-las em forma e em movimento pode mostrar o que elas não encontram em outra via de figuração e de laço nos significantes. $\mathrm{O}$ ato do fantoche é um indício de um texto mudo a serviço do desejo do sujeito ${ }^{4}$.

\section{Mudar o lugar de declaração}

Citemos o exemplo de Yvan, 5 anos, trazido por sua mãe que não suporta mais que ele se cale assim que sai de casa. Junto dela, ele "fala sem parar". Outro tipo de "fuga" é evocado no primeiro encontro: o pai os abandonou e sobre isso a mãe não quer dizer mais nada, principalmente a seu filho, mas acrescenta que o mutismo de Yvan fora de casa começou pouco depois do abandono. As dificuldades na escola são importantes, pois ele interage somente com algumas meninas; os adultos o assustam, principalmente os homens. Assim, somos prevenidos de que ele não falará conosco. Portanto, não é surpreendente que Yvan, quando sozinho conosco, adormeça na 
cadeira ou olhe em todas as direções. As poucas perguntas que fazemos e as tentativas de relance sobre o que a sua mãe dissera não levam a resposta alguma. Mesmo assim, ele fica e olha a caixa de jogos. Assim propomos que ele se aproxime dela e que pegue no que deseja. Ele mexe nos brinquedos, toca nos fantoches e pega um - o de uma mulher com cabelos brancos: uma avó. Ele a contempla, mas não a utiliza. Intervimos para indicar-lhe como utilizá-la e propomos que o fantoche diga algo. Yvan ajusta a sua mão na forma, mas nenhuma palavra é dita. O contato pode ser feito, o que é uma promessa de jogo e de significação, mas nenhuma palavra é dita até o fim do encontro, que interrompemos ao propor ao garoto que venha na semana seguinte. Pequena aquiescência com a cabeça como resposta. Sua mãe também concorda, mesmo que cética com o que possa acontecer.

Na semana seguinte, Yvan entra sozinho na sala. Não responde à nossa saudação, mas os nossos olhos se encontram e vai diretamente à caixa de brinquedos da qual tira o fantoche "avó". Mas ele pega também em outro (um homem com uniforme) e olhando os aproxima. Intervimos propondo que nos dê um fantoche e que invente uma história. Imediatamente, Yvan nos dá o do homem uniformizado. Vestimos o boneco na mão e ele faz o mesmo com o dele. Em seguida, fazemos uma troca de movimentos e palavras para tentar saber quem é e o que quer esta "senhora".
Yvan consente em responder com a cabeça, indicando quando concorda ou não. O jogo consiste em ver esta "senhora" se aproximar do homem uniformizado e se mostrar... Mas sem uma palavra.

As sessões seguintes foram do mesmo modo e com a mesma trama, mas a troca entre os fantoches se intensifica. Sempre sem palavras de Yvan, que a cada vez vem decidido e contente. Sua mãe parece menos animada, pois esperava uma mudança imediata e revela que seu filho a deixa furiosa e agressiva com ele. O que mudou, diz ela, é que o filho pergunta com insistência o que aconteceu com seu pai. E ela não sabe o que responder, pois existe um segredo que deve calar: o mutismo é partilhado.

Ao fim de dois meses, eles não voltam mais. $\mathrm{O}$ sintoma estava bem aqui "na verdade do casal familiar" (Lacan, 2001, p. 373), e a proposta de fala encontrou uma impossibilidade de palavra, uma impossibilidade de dizer.

A escolha de Yvan de animar um fantoche para dizer sem falar é uma ilustração da capacidade da criança de encontrar o que o conforta no enquadre transferencial. Com efeito, os fantoches são "nossos" e, logo, são constitutivos do nosso espaço transferencial e solidários da regra fundamental de dizer tudo, como o desejo do analista "de obter a diferença absoluta” (Lacan, 1973, p. 248). Portanto, usar o fantoche é um ato de transferência, o que diferencia esse 
“jogo" dirigido das práticas terapêuticas lúdicas com fantoches (como certas terapias pelo jogo), em que o terapeuta partilha ativamente o jogo com a criança, misturando com ele os seus fantasmas.

\section{Psicose e fantoche}

Uma objeção à hipótese de um espaço metafórico do fantoche aparece quando refletimos sobre a particularidade da psicose. Objeção relativa ao tipo de laço entre o psicótico e o fantoche, criado ou encontrado. A relação com o objeto não existe imediatamente, metaforicamente, mas metonimicamente. A delegação e a sublimação ficam suspensas para que se forme uma indistinção, pois toda relação metonímica com um objeto concreto, na psicose, sobretudo se fabricado, é uma criação que produz uma unificação do lugar. Um espaço metonímico é, assim, o primeiro tempo indispensável a se criar no espaço psicoterapêutico das psicoses com a ajuda do fantoche para, em seguida, eventualmente, abrir caminho para outros efeitos metafóricos parecidos e articulados em três dimensões: a elaboração da falta de objeto, o limite de transbordo do imaginário com o enquadramento de uma mediação imaginária, e as tentativas de se representar através da projeção. Para isso, utilizaremos a nossa prática clínica com os fantoches terapêuticos em hospital-dia.

\section{Dispositivo com fantoches e psicoterapia de psicoses infantis}

Fazer a proposta do uso psicoterapêutico dos fantoches com crianças psicóticas nas instituições responde a vários argumentos. Primeiramente, os de cunho teórico, na medida em que, a partir dos exemplos da clínica psiquiátrica clássica e do domínio da Arte Bruta, sabemos que o princípio de base que poderíamos extrair do uso terapêutico do fantoche é a relação metonímica que o sujeito inicia com ele, acentuada em sua fabricação, na manipulação, no vestir e na nomeação. Também de cunho ético, pois a proposta feita a uma criança psicótica de participar de uma oficina de fantoches, onde lhe será pedido para fabricar e manipular o seu próprio fantoche, não é só uma proposta de atividade, mas um suporte de criação de um lugar que seja habitado mais uma vez por ela. Toda instituição de saúde deveria proporcionar momentos de fabricação, momentos apoiando o esforço de juntar o que o destino psicótico dispersa (Oury, 1989). Os fantoches podem constituir esse tipo de oferta, mas sempre se submetendo à vontade do sujeito de recusar. Por fim, de cunho terapêutico, resultado de uma prática suficientemente longa para poder localizá-lo, à medida em que essa mediação, para o psicótico que tenta resolver a sua relação com o Outro, é um possível suporte, vetor, 
de uma distância pacificadora. No entanto, a criação, sozinha, não é suficiente para relatar tal trabalho de pacificação, sendo necessário um dispositivo para que ele se oriente.

Tal dispositivo consiste em fazer existir um corte entre o sujeito e o seu fantoche, para que o fantoche fabricado não seja um duplo nem semelhança, mas que fique marcado pela falta, por um ponto de fuga. Quatro elementos estão localizados nessa perspectiva e formam a estrutura do que chamamos "espaço do fantoche", em psicoterapia: o distanciamento, o olhar, a voz e a nomeação.

\section{O distanciamento}

Um dos objetivos principais do trabalho terapêutico com as crianças psicóticas é, de uma maneira geral, que apareça um distanciamento suficiente na sua relação com o mundo. É um dos efeitos da estabilização. Com os fantoches, o trabalho de distanciamento é o centro da relação que induzem. A arte do fantoche repousa sobre ela, o que dá como resultado fazer existir simbolicamente uma ilusão, tanto do lado do espectador quanto do manipulador: a de fazer crer que a matéria pode se animar. Ora, toda a tradição do fantoche faz parecer que um e outro, espectador e artista, têm prazer no ato de ir contra essa ilusão, pois é preciso que tenham uma distância dela.

Aqui, a dificuldade reside no fato de que o trabalho de distanciamento é uma operação essencial sobre a articulação do simbólico e do imaginário, o que permite um relaxamento da influência do segundo pelo primeiro e a sua retomada, durante o breve tempo da representação. Ora, a psicose é marcada por uma falha da ordem simbólica à qual falta o significante primordial para orientá-lo, o que é acompanhado por desordens da relação com o imaginário e da relação sem distância com o real. Assim, a diferença entre si e a imagem não está bem estabelecida pela criança psicótica. E, se considerarmos a hipótese de que o fantoche é uma espécie de depósito narcísico, sendo um objeto especular, não será espantoso encontrar todos os fenômenos de regressão tópica ao estado do espelho nessas crianças na presença de um fantoche que fabricaram. Aliás, esse registro imaginário é onde o controle do Outro sobre o sujeito tende a se revelar. Certamente que os fantoches podem, em certas ocasiões, se encarnar e tornarem-se reais, de tal maneira que 
assistimos, por vezes massivamente, a ataques de distanciamento. Trata-se de um, esquematicamente, "des-distanciamento" nos dois sentidos opostos: no sentido da fusão e no da perseguição.

Em um caso de "des-distanciamento", o papel dos terapeutas é de lembrar que são os mesmos princípios do teatro dos fantoches, principalmente que cada fantoche tem o seu próprio nome e que esse nome não deve mudar. É a sua identidade. Também é necessário insistir que, para falar, só os fantoches podem se mostrar, seus "proprietários" devem ficar escondidos atrás do palco. Esses lembretes servem essencialmente para lembrar os elementos da estrutura do espaço fantoche como balizas para que cada sujeito possa se orientar em direção aos efeitos de metaforização. E um dos sinais tangíveis do acesso a um começo de metaforização é o prazer, ou mesmo júbilo que as crianças podem encontrar manipulando os seus fantoches ou o os fantoches de outros. Esses momentos fugazes são uma subtração do real menos massiva no seu controle do sujeito, e uma suposição, dentro de e para o campo escópico, de uma identificação especular com a qual é possível jogar.

\section{Primeiro a metonímia}

Mas neste trabalho de posicionamento com relação ao Outro que o fantoche permite, - e, em função do que desenvolvemos anteriormente, antes de qualquer possível metaforização - a emergência de um laço metonímico com o fantoche aparece. Esse tipo de laço caracteriza a relação que muitas crianças autistas têm com certos objetos dos quais não se separam, dia e noite. Tais objetos são uma relação de continuidade com eles mesmos, sem cortes, o que tem um caráter altamente defensivo. Assim, essa criança convidada a participar do grupo apresentava fantoches que não podiam largar uma serpente de plástico, que ela punha enrolada no pescoço e que levava para todos os lados. O primeiro momento de trabalho, com o qual ele aos poucos concordou, foi de por de lado o objeto para investir na construção de seu fantoche. Esse homem, metade humano, metade animal, com uma cabeça impressionante e estranha, teve também uma dimensão metonímica, sem um verdadeira distanciamento. . O consentimento suplementar da criança foi o de passar para trás da cena para "cortá-la" dele mesmo quando ele a mostra, o que é acompanhado na instituição pelo fato de poder largar a sua serpente do pescoço para passar a mostrá-la e fazer com que ela fale como um fantoche. Portanto, essa metonimização é a de incentivar, acompanhar, mas também limitar um trabalho de distinção. 
Com a relação metonímica com os objetos da psicose, Ginette Michaud demonstrou que ela pode ser suporte de um modelo de transferência na relação terapêutica com o psicótico criando um espaço metonímico. Esta constatação vem da sua prática clínica com as mediações do tipo antropomórfico (esculturas feitas com plasticina). A partir daí, o dispositivo deve favorecer o que é endereçado ao outro e, no espaço do fantoche, o espectador e os terapeutas. É nessa direção que existe uma mudança possível capaz, pelo distanciamento que supõe, de fazer com que a relação metonímica possa se desenvolver entre o sujeito e o seu fantoche. Ora o olhar e a voz são os dois vetores privilegiados neste trabalho.

\section{O olhar}

Algumas palavras sobre o dispositivo são necessárias para que se entenda bem a dinâmica de trabalho. Depois que se constrói o fantoche, o que geralmente ocupa metade da sessão, propõe-se às crianças mostrá-los, individualmente, atrás do teatro de fantoches. É-lhes dito que os fantoches devem falar unicamente lá, e também que um fantoche pode chamar outros para brincar junto a ele e fazerem o espetáculo. É importante que aqueles que não mostram seu fantoche sejam espectadores do espetáculo dos outros, exigência que nem com todas as crianças é fácil de respeitar. Aliás, os que têm mais dificuldade de respeitar o lugar de espectadores são também os que respeitam menos o momento de fazerem eles mesmos o espetáculo do teatro. Mas o que está em jogo nesse teatro de fantoches, que materializa uma linha de separação entre os dois espaços complementares? Trata-se de uma representação da ausência e da presença, condição necessária à simbolização? De fato, mas também de uma organização do gozo, que é essencialmente sobre o olhar como objeto pulsional. Trata-se, com efeito, de brincar consigo mesmo (com os objetos internos) quando se manipula o fantoche e, principalmente, para outro que não se vê; o espectador a quem se dirige o prazer. Pode também ser possível brincar com o espectador como na pura tradição do teatro de fantoches. No entanto, na visão da criança que manipula o fantoche ela está escondida do público: é o seu fantoche que se oferece ao olhar dos outros. É por meio do fantoche, à distância, que o sujeito 
está presente para os outros e se mostra. Com a manipulação, a criança se ausenta dela mesma e se distancia do seu fantoche para o outro: o caminho da falta do objeto está aberto. O dispositivo do teatro de fantoches é assim um meio de dominar o olhar e dirigi-lo para outra direção. Isso é um ponto importante com relação às crianças que, tendo que levar o Outro em conta, reagem de uma maneira defensiva e de um modo persecutório aos sinais de sua presença, passando pelo olhar, pela voz, e, menos significativamente, pela postura. Todos os vetores de um desejo vivido como uma ordem à qual o sujeito não pode escapar.

\section{A voz, a nomeação}

Antoine Vitez aponta que o fantoche tem uma relação particular com a fala. Ao fazer falar demais um fantoche, corre-se o risco de que ele perca o seu sentido, de não ser mais um fantoche, pois seria parecido demais com o humano, ser de fala. O que faz a sua especificidade é o gesto, o movimento pelos quais ele fala com sua própria sintaxe (Vitez, 1980, p. 23-31). Outra dimensão da relação com a fala no trabalho com os fantoches é o de saber que o enunciado (o que "diz" um fantoche) não coincide com o emissor (o fantoche ele mesmo); essa voz vem sempre de outro lugar, com uma diferença espacial e uma entonação quase sempre não familiar.

Esses elementos podem igualmente participar de um certo controle do registro pulsional da voz, importante na psicose, acentuando a pressão do fantoche sobre o sujeito. A voz que soa, que intima, que invade as alucinações, que ecoa e se impõe vinda de um Outro externo são diferentes modalidades presentes na psicose infantil. A proposta de fazer falar o fantoche regulando o enunciado e a enunciação, como por aceder a outros modos de significação pelo jogo fora da palavra enunciada, pode ser apropriada por algumas crianças para operar uma metabolização e uma sintonização de seu delírio. Outras não conseguirão e a estabilização seguirá diferentes vias, dispositivos ou somente o seu esforço. Em todo caso, é a direção do trabalho que seguimos, reconhecendo ao enquadramento do teatro de fantoches uma dimensão a explorar.

A dimensão relacionada à voz se completa com a importância da nomeação. Cada fantoche terá um nome próprio que deverá guardar até o fim. Nomear é um ato que separa, cria uma distância e faz a base de uma metaforização que poderá seguir a metonímia de Antoine Vitez; a nomeação de um fantoche reduz o aperto dessa contiguidade. Não existe fantoche que não seja nomeado, assim como humanos que não se identifiquem com um nome. 


\title{
E o autista?
}

A compreensão psicanalítica dos sujeitos autistas, que leva em conta suas construções defensivas e os seus modos de investimento, mostra a relação específica com um objeto pulsional em particular: a voz (Maleval, 2009). Se podemos nos referir ao desenvolvimento anterior relativamente às três dimensões do espaço do fantoche nas psicoterapias das psicoses (o distanciamento, o olhar e a voz), sublinhamos que nossa experiência nos indica que as crianças autistas às quais propomos este dispositivo o utilizaram para poder usar suas vozes. Ao contrário de suas atitudes habituais de se manter a distância do mundo que as rodeia, elas usam plenamente o dispositivo para fazer falar o seu fantoche, ilustrando assim que o gozo vocal suporta um desaparecimento na confrontação ao olhar do outro que também desaparece, única condição para lhe dirigir qualquer coisa, mesmo embrionária.

\section{Conclusão}

Os recursos do fantoche em psicopatologia clínica são inúmeros e a história de seu uso psicoterapêutico é rico em experiências eficazes. Entretanto, é na pesquisa contínua que trabalhamos, associando a reflexão clínica ao testemunho de todos os sujeitos que encontraram nos fantoches um caminho para exprimir a sua capacidade de criatividade. E sem dúvida alguma que as evoluções do teatro de fantoches, assim como os comentários e pesquisas associadas, podem ser suportes prolíferos para a pesquisa e as intervenções clínicas.

THE PUPPET AS MEDIATION FOR MENTAL SUFFERING

\begin{abstract}
The presence of puppets in psychotherapeutic devices exists for nearly a century, and we can say that today they are among the mediations often used in treating children and adults. In this article we focus on the field of clinical psychopathology and on the place that may be attributed to the puppet in the encounter with issues that cross the practice of a day hospital for children of a Medical Psychology Center (CMP).
\end{abstract}

Index terms: puppet therapy; therapeutic mediation; psychic suffering; clinical psychopathology. 
LOS TÍTERES COMO MEDLADORES DE LOS SUFRIMIENTOS MENTALES

\section{RESUMEN}

La presencia de los titeres en los dispositivos psicoterapéuticos existe hace casi un siglo, y actualmente está entre las mediaciones que más se utilizan tanto en el tratamiento de los niños cuanto de los adultos. En este articulo se plantea el campo de la psicopatología clinica y el lugar que puede atribuirse a los titeres en las cuestiones que cruzan la práctica de un hospital-día de niños de un Centro Médico-Psicológico (CMP).

Palabras clave: terapia con titeres; mediación terapéutica; sufrimiento psíquico; psicopatología clínica.

\section{REFERENNCIAS}

Lacan, J. (1966). La psychanalyse et son enseignement. In J. Lacan, Écrits. Paris, França: Seuil.

Lacan, J. (1973). Le séminaire, livre XI: Les quatre concepts fondamentaux de la psychanalyse. Paris, França: Seuil.

Lacan, J. (1981). Le séminaire, livre III: Les psychoses. Paris, França: Seuil.

Lacan, J. (2001). Note sur l'enfant. In J. Lacan, Autres écrits (pp. 373-374). Paris, França: Seuil.
Maleval, J. C. (2009). L'autiste et la voix. Paris, França: Seuil.

Michaud, G. (2004). Essais sur la schizophrénie et le traitement des psychoses. Tome 1. L'impossible réalité. Ramonville-St Agne, França: Erès.

Oury, J. (1989). Création et schizophrénie. Paris, França: Galilée.

Valéry, P. (1942). Mauvaises pensées et Autres. Paris, França: Gallimard.

Vitez, A. (1980). L'âme et la partie pour le tout. Théâtre public, (34/35), 23-31.

\section{NOTAS}

1. Mesmo tipo de estrutura que os Centros de Atenção Psicossocial (CAPS ) brasileiros.

2. N do T.: "Qui regarde sa main, se voit être ou agir là où il n’est pas” (Valéry, 1942, p. 84).

3. N do T.: "j' entends pas discours y compris des actes, des démarches, les contorsions des marionnettes prises dans le jeu" (Lacan, 1981, p. 63).

4. N do T.: “C'est-à-dire qu’à tous les niveaux du jeu de sa marionnette, il emprunte quelques éléments pour que leur séquence suffise à témoigner d'un texte, sans lequel le désir qui y est convoyé ne serait pas indestructible" (Lacan, 1966, p. 446).

pascal.lemalefan@orange.fr 17, rue Lavoisier 76820 - Mont-Saint-Aignan cedex - France. tsvrebelo@gmail.com 17, rue Lavoisier 76820 - Mont-Saint-Aignan cedex - France.

Recebido em janeiro/2015. Aceito em abril/2015. 